\title{
Reviewing Canada's National Framework of Criteria and Indicators for Sustainable Forest Management
}

\author{
by S.R.J . Bridge ${ }^{1}$, D. Cooligan², D. Dye ${ }^{3}$, L. Moores ${ }^{4}$, T. Niemann ${ }^{5}$ and R. Thompson ${ }^{6}$
}

\begin{abstract}
The Canadian Council of Forest Ministers' (CCFM ) framework of Criteria and Indicators (C\&I) for Sustainable Forest M anagement, published in 1995, provide a science-based framework to define and measure Canada's progress in the sustainable management of its forest. In 2001, the CCFM launched a review of its C\&I to ensurethe continued relevance of the indicators to Canadian values and to improve the ability to report on indicators. This paper describes the threestep review process, which engaged a broad array of representatives of various sectors of society. First, focus groups were used to identify public values, issues and concerns with respect to the sustainable use of Canada's forest. Second, technical experts from across the forest sector revised the indicators. Third, the revised C\&I were validated with users of the framework. The revised framework, released in September 2003, consists of six criteria and 46 indicators. The number of indicators has been reduced, compared to the 1995 framework, by focusing on indicators that are most relevant to Canadians' values, are most often measurable with available data, and are understandable to policy makers, forest managers and an informed public. Links between criteria are better defined and, in some cases, indicators address multiple values under different criteria. A number of tools and techniques originally developed for use at the sub-national level were adapted for use at the national level in this review. Canada's experience with reviewing its indicators may serve as an example and model to other countries now considering reviewing their national $C \& \mid$ frameworks.
\end{abstract}

Key words: Canada, Canadian Council of Forest M inisters, criteria and indicators, C\&I, sustainable forest management, review

\section{RÉSUMÉ}

Le cadre de référence sur les Critères et les Indicateurs d'aménagement forestier durable du Conseil canadien des ministres des forêts (CCM F), publié en 1995, constitue un cadre scientifique pour définir et mesurer les progrès du Canada en matière d'aménagement durable de ses forêts. En 2001, le CCM F a amorcéune révision de ses C \& I pour s'assurer du maintien de la pertinence des indicateurs relativement aux valeurs canadiennes et pour améliorer la capacité de faire état des indicateurs. Cet article décrit le processus de révision en trois étapes qui a impliqué plusieurs représentants de divers milieux sociaux. En premier lieu, des groupes de discussion ont été utilisés pour identifier les valeurs, les enjeux et les questions du public relativement à l'utilisation durable des forêts du Canada. En second lieu, les experts techniques de tout le secteur forestier ont révisé les indicateurs. Et en troisième lieu, les $C \&$ I révisés ont été validés avec les utilisateurs du cadre de référence. Le cadre révisé, publié en septembre 2003, consiste en six critères et 46 indicateurs. Le nombre d'indicateurs a été réduit par rapport au cadre de 1995, en se concentrant sur les indicateurs qui sont les plus pertinents en fonction des valeurs des Canadiens, les plus souvent mesurables à partir des données existantes et qui sont les plus compréhensibles aux yeux des décideurs, des gestionnaires forestiers et du public informé. Les liens entre les critères sont mieux définis et, dans certains cas, les indicateurs abordent plusieurs valeurs retrouvées sous différents critères. Certains outils et techniques originalement élaborés pour utilisation régionale ont été adaptés pour une utilisation nationale Iors de cette révision. L'expérience du Canada en matière de révision de ses indicateurs pourrait servir d'exemple et de modèle à d'autres pays qui considèrent présentement la révision de leur cadre national de $\mathrm{C} \& \mathrm{I}$.

Mots clés : Canada, Conseil canadien des ministres des forêts, critères et indicateurs, aménagement forestier durable, révision

\footnotetext{
${ }^{1}$ Criteria and Indicators Policy Advisor, Policy, Planning and International Affairs, Natural Resources Canada - Canadian Forest Service, 580 Booth Street, Ottawa, Ontario K1A 0E4. E-mail: sbridge@nrcan.gc.ca. Web site: www.ccfm.org. (Author to whom correspondence should be addressed.)

${ }^{2}$ National and International Forestry Advisor, Ontario M inistry of Natural Resources, 70 Foster D rive, Suite 400, Sault Ste. M arie, Ontario P6A 6V5. E-mail: dan.cooligan@mnr.gov.on.ca.

${ }^{3}$ Coordinator, Forest Ecosystems Branch, Saskatchewan Environment, P.O. Box 3003, Prince Albert, Saskatchewan S6V 6G1. E-mail: dye@derm.gov.sk.ca.

${ }^{4}$ Director, Ecosystem Health, Newfoundland and Labrador Department of Natural Resources, P.O. Box 2006, Corner Brook, Newfoundland A2H 6]8. E-mail: Imoores@mail.gov.nf.ca.

${ }^{5}$ Forest Practices Branch, BC Ministry of Forests, P.O. Box 9513, Stn. Prov. Gov't.,Victoria, British Columbia V8W 9C2. E-mail: Tom.Niemann@gems6.gov.bc.ca.

${ }^{6}$ Researcher, Forest Protection Division, Alberta Sustainable Resource Development, 1176 Switzer Drive, H inton, Alberta T7V 1V3. E-mail: Rory.Thompson@gov.ab.ca.
} 


\section{Introduction}

Canada's forest is essential to the long-term well-being of its communities, economy, and environment. Almost half of Canada's land area is forested, providing Canadians with a multitude of benefits. Asstewards of $10 \%$ of the world's forest, Canada has accepted its responsibility to maintain its forest in a healthy state and to manage it in a sustainable manner.

Canada's commitment to sustainable forest management was enshrined in its 1992, 1998 and 2003 national forest strategies (CCFM 1992, 1998; NFSC 2003), which were developed by governments and others concerned with the management of Canada's forest. Canada and the international community also recognized the importance of sustainable forest management in 1992 at the United Nations Conference on Environment and Development (UNCED) with the adoption of a Statement of Forest Principles. The concept was embodied in Chapter 11 of the conference's action plan, Agenda 21.

The release of the Canadian Council of Forest Ministers' (CCFM ) framework of Criteria and Indicators (C\&I) of sustainable forest management in 1995 (CCFM 1995), and subsequent reports in 1997 and 2000 (CCFM 1997, 2000), were important steps in implementing Canada's commitments in the national forest strategies, as well as the forestry commitments made at UNCED. The CCFM C\&I provide a sciencebased framework to define and measure Canada's progress in the sustainable management of its forest. The criteria represent forest values that Canadians want to enhance or sustain, while the indicators identify scientific factors to assess the state of the forest and measure progress over time.

Sustainable forest management is an adaptive process and assessing sustainability is a continuous activity. The 1995 C\&l framework was expected to evolve as society's values changed, data availability improved, and knowledge of the environmental, social and economic aspects of sustainable forestry improved. Building on its experience reporting on the C\&l in 1997 and 2000, the CCFM launched a review of its C\&l framework in September 2001. The goal was to ensure the continued relevance of the indicators to Canadian values and improve the ability to report on indicators to assess progress toward sustainable forest management at the national level. This review was completed in September 2003 with the release of the revised C\&I framework (CCFM 2003).

This paper describes the process that Canada undertook to review its national framework of $C \& l$. While there are many examples, particularly at the local level, of initiatives and processes to develop an initial set of $C \& \mid$ (e.g., Natural Resources Canada 2000), there are relatively few examples of how national level $C \& \mid$ initiatives have undertaken a review of their indicators after producing one or more $C \& \mid$ reports. This paper shows how Canada was able to learn from its earlier reporting efforts and how many of the tools and techniques used to develop indicators at the sub-national level can be successfully adapted for use in a national level review.

A growing number of countries have released their first national $C \& I$ reports and are now considering reviewing and revising their C\&I. For example, the 12 member countries ${ }^{1}$

\footnotetext{
1The 12 member countries of the M ontréal Process are: Argentina, Australia, Canada, Chile, China, Japan, Republic of Korea, M exico, New Zealand, Russian Federation, USA, and Uruguay.
}

of the Working Group on Criteria and Indicators for the Conservation and Sustainable Management of Temperate and Boreal Forests, otherwise known as the "Montréal Process," have announced their intent to review and refine the M P C\&I framework (Montréal Process 2003). Canada's experience in reviewing its CCFM C\&I framework may provide useful insights to countries who are now considering reviewing their national $C \& \mid$ frameworks.

\section{Why Review the CCFM C\&I?}

Almost all (93\%) of Canada's forest lands are publicly owned and most of the timber-productive forest is managed under provincial or territorial jurisdiction. The Canadian Council of Forest M inisters was established in 1985 to allow the 14 federal, provincial and territorial ministers with responsibility for forests to cooperate more closely in national and international matters. The council sets the overall direction for forest stewardship and facilitates the development of policies and initiatives in the Canadian forest sector. In 1993, The CCFM established the C\&I Task Force, composed of federal, provincial and territorial representatives, to guide the $C \& I$ initiative. This task force led the framework review with support from the $C \& \mid$ secretariat, housed at the Canadian Forest Service, in Ottawa.

Since the CCFM 's first C\&I framework was published in 1995 the capacity of information systems has increased, approaches to forest inventories have changed, data availability has improved and advances in science have improved our understanding of ecosystems. In 1999, a committee of C\&I Task Force members and external science experts from economic, social and environmental fields examined the indicators in the CCFM C\&I framework in an effort to identify which indicators should be adopted for future reporting on SFM at the national level (unpublished CCFM report). The committee found that for many indicators data were either unavailable or inaccessible nationally. Furthermore, in many cases, CCFM indicators were poorly worded, making data requirements difficult to define. The committee also found that while most of the CCFM indicators were compatible with the Montréal Process C\&I framework, there was room for improvement so that information collected for the CCFM $C \& I$ could be used more fully to report internationally on the Montreal Process C\&I (Canada reports on both the CCFM and MP C\&I and information collected for the CCFM C\&I forms the basis of Canada's contribution to theM P C\&I). The committee recommended that a technical committee be struck to revise and modify the indicators to improvethe ability to report and strengthen links to other $\mathrm{C} \& \mathrm{I}$ frameworks.

The release of National Status 2000 (CCFM 2000), the CCFM 's first attempt to report on all of the indicators in its C\&I framework, confirmed many of the findings about data requirements and availability in the 1999 committee report. Based on the committee's findings, the CCFM 's experience in producing the 1997 and 2000 reports, and the recognition that sustainable forest management is an adaptive process, the CCFM launched a review of its C\&I framework in 2001. The overall goal of the review was to improve the relevance and efficiency of the indicators for reporting on and assessing progress toward sustainableforest management at the national level, to improve linkages with other international C\&l processes, particularly the Montréal Process, and consider benchmarks and targets. 


\section{The Review Process}

The CCFM recognized that in order to create an effective set of C\&I that has broad acceptance, affected parties needed to have meaningful input at the beginning of the process and the process needed to be as transparent as possible, with adequate follow-up to ensure everyone remained informed. Accordingly, the CCFM C\&I review process was designed to be inclusive, engaging a broad array of representatives of various sectors of society and technical experts from start to finish in a three-step process:

1. Identify public values, issues and concerns.

2. Revise the indicators with technical experts.

3. Validate the revised $C \& I$ with users.

Considerable work has been done, principally at thelocal level, refining tools and techniques to develop sets of indicators for sustainable forest management (Williams et al. 1998, Mendoza et al. 1999, Prabhu et al. 1999, Natural Resources Canada 2000, USDA 2002) and common pitfalls associated with developing indicators have been pointed out (Duinker 2001). M any of these tools and techniques were adapted for use at the national level to facilitate the CCFM c\&l review.

\section{Identify public values, issues and concerns}

Sustainability is a human value, not a fixed, independent state of social, economic, and ecological affairs. As such, it is not an "absolute" because it depends on social values, issues and concerns that can vary over time. Indicators provide quantitative and qualitative measures related to those values, issues and concerns. As society's values around sustainability change over time, $C \& \mid$ frameworks need periodic revision to ensure that they continue to accurately and efficiently reflect these changing values regarding sustainable forest management. The first step, therefore, in reviewing the CCFM C\&I framework was to confirm the values, issues and concerns of Canadians.

In December 2001, a focus group study was commissioned to help identify Canadians' values, issues and concerns with respect to the sustainable use of the forest and to categorize and prioritize these values (Compas 2002). The intent of the study was to gather input from a broad crosssection of society. To increase the quality of the participants' input, the study was limited to audiences having at least some knowledge of and interest in forest issues. Fourteen focus groups targeting members of the general public, people who use the forest for recreation, Aboriginals, woodlot owners, community leaders, environmental non-governmental organization (ENGO) representatives, and timber and non-timber forest products industry representatives were conducted in five forest-based communities across Canada plus M ontréal and Vancouver between December 4 and 18, 2001. In total, 113 people participated, of which one-third were women.

The focus groups proved to be a cost-effective way of gathering input from a variety of Canadians who are interested in forest issues, but are not necessarily experts in sustainable forestry. The workshop setting allowed participants to be guided through an interactive process to efficiently identify and discuss their values. Similar processes have been used effectively with groups of stakeholders at the local level (e.g., Williams et al. 1998). Dozens of different values, issues and concerns were identified, but several were common to most groups and were given high priority rankings (Table 1). Similar values have been identified in past national surveys (Forestry Canada 1992, Natural Resources Canada 1997) as well as sub-national studies and surveys (e.g., Robinson et al. 1997; Von M irbach and Johnson 1998; Sanderson et al. 2000a,b). As might be expected, different interest groups emphasized different values. H owever, there generally seemed to belittle regional influence on the values identified. For example, woodlot owners in Atlantic Canada identified values similar to those of their compatriots in central Canada and gave them similar priorities; likewise, ENGO representatives in central Canada and western Canada.

The results of the focus group study helped to confirm that the six CCFM criteria (Table 2) are sufficiently broad to cover all environmental, economic and social aspects of sustainable forest management. The CCFM criteria also have linkages to other processes in Canada, such as local-level indicators, Canadian Standards Association (CSA) certification and provincial State of the Forest reporting, and correspond well with criteria found in other national level C\&I frameworks, including those of nine other multi-national initiatives used by some 150 countries (FAO 2001). This similarity in criteria amongst processes has been internationally acknowledged as valuable and may help facilitate future international reporting on sustainable forest management (FAO 2003, IISD 2004).

\section{Revise the indicators with technical experts}

In February 2002, the Task Force established six Technical Working Groups (TWGs), one for each criterion, to review the indicators in the $C \& \mid$ framework and recommend revised indicators to the Task Force. Each TWG was chaired by a Task Force member, or alternate accepted by the Task Force, and was comprised of experts from the federal, provincial and territorial governments; academia; the Aboriginal community; industry; and non-governmental organizations. Two academic experts also advised the TWGs (Fig.1).

The TWGs for criteria 1, 2, 3, 5 and 6 met three times in 2002. At the first meeting in M arch, the TWG members were asked to produce a preliminary list of indicators for their criterion. At the second meeting in April, the TWGs were asked to sort through this initial list of draft indicators and reduce the list to less than 20 potential indicators per criterion. Participants were given a list of selection attributes to screen indicators (described below), and each group was asked to describe the rationale for each indicator and give measurement units along with additional information such as approaches to measurement, interpretation, reference values, and links to other $C \& \mid$ processes. During the summer, each of the five groups worked on their own, meeting several times by email or teleconference, to further refine their indicators. The groups came back together for a third and final time in August 2002 to finalize the list of recommended indicators for each criterion.

In early October 2002, a sixth Technical Working Group assembled to review the indicators under criterion 4. Criterion 4 deals with forest ecosystem contributions to global ecological cycles, but the indicators in the original framework mostly relate to the global carbon cycle. This TWG was able to take advantage of the large amount of work being carried out by federal and provincial agencies 
Table 1: Some common reasons forests are important to Canadians and some important issues identified by focus group participants

Reasons

- Provide habitat for plants and animals

- Soak up carbon and provide oxygen

- Filter water and control water flow

- Prevent soil erosion

- Provide medicines, food, and other products

- Source of recreation, relaxation, spiritual and educational opportunities

- Source of employment and economic growth

Issues

- Rate of cut

- Protecting wildlife, habitat and wetlands

- Enforcement of existing laws and regulations

- Public involvement in decision-making

- Maintaining large, wild, forested areas

- Aboriginal and treaty rights

\section{Table 2: The six Criteria in the CCFM C\&I framework}

Biological Diversity

Ecosystem Condition and Productivity

Soil and Water

Role in Global Ecological Cycles

Economic and Social Benefits

Society's Responsibility

and committees on measuring forest contributions to the carbon budget, which allowed the TWG to meet just once to develop a revised set of indicators for this criterion.

Later in October 2002, TWG Chairs met with the expert advisors to compile and integrate the six separate sets of indicator recommendations, which contained a total of 106 indicators, into a single, cohesive framework. The Chairs reduced this number, largely by combining similar indicators recommended by two or more TWGs. This required a choice of the best criterion under which to place an indicator relevant to morethan onecriterion, and underscored the importance of providing a description of linkages among criteria as part of the framework. The TWG Chairs then circulated their compilation to the TWG members for feedback in December 2002 and made final revisions in January 2003.

In February 2003, The TWG submitted 53 indicators to the Task Force for consideration to improve the CCFM Framework of Criteria and Indicators of Sustainable Forest Management. An important part of this submission were two technical supplements ${ }^{2}$ that described each indicator in more detail, including (1) the rationale for its development, measurement units, possible data sources, and (2) links to the original CCFM C\&I and Montréal Process C\&I. This type of detailed documentation had not been available for the original $C \& I$ and is a valuable tool for communicating the revised framework to users.

\footnotetext{
${ }^{2}$ Available online at: www.ccfm.org/review_e.html.
}

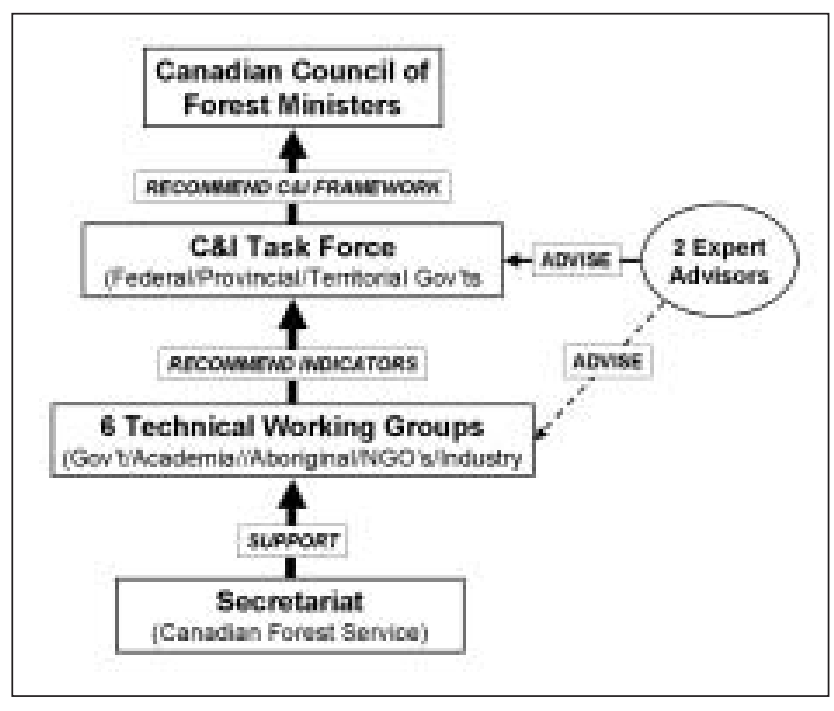

Figl. Roles and reporting structure of groups engaged in the CCFM C\&I review.

The process in which the TWGs engaged was similar in many respects to the "mixed approach" to selecting indicators described by Mendoza et al. (1999). Technical Working Group members were free to add, delete or create indicators, but were not starting "from scratch" as they had for the original CCFM C\&I. Experts brought a diversity of knowledge and points of view to the table and those who represented an organization were encouraged to consult with their organization's members throughout the review. The process provided a broad exchange of views that ensured that the recommended indicators would be based on the best available knowledge.

During their review, the TWGs considered the values identified in the focus group study, analyzed the 1995 CCFM indicators as well as indicators from other C\&l processes, and considered whether there were additional long-term issues of critical concern to sustainable forest management in Canada for which indicators should be developed. Each potential indicator was assessed using the following selection attributes (see Table 3):

- relevant to the criterion;

- measurable based on scientifically valid, empirical measurements that can be consistently repeated over time, with data that are both practical and fiscally feasible to collect;

- understandable, not only to forest managers, but also to an informed public;

- can be forecast into the future with reasonable accuracy; and,

- availability of reference values.

These selection attributes are similar to those used in other indicator development processes (e.g., CFS 1994, CBD 1996, Smith et al. 1999, Global Reporting Initiative 2000, ISDI 2000, Duinker 2001, M CPFE 2001).

The TWGs also considered whether or not each indicator should be identified as a core indicator, a supporting indicator or a potential indicator. Core indicators relate to values, issues or concerns that are clearly of great interest to Canadians. They raise public awareness and focus public 


\section{Table 3: Selection attributes for screening indicators}

Relevant - each indicator must relate clearly to a particular criterion, and should represent significant information about the values embodied by the criterion. An indicator must be sensitive and responsive to change in the sense that management actions and other forces can readily influence its behaviour.

Measurable - an indicator should be based on available or easily obtainable, scientifically valid, empirical measurements that can be consistently repeated over time to observe trends. Obtaining indicator data must be practical and fiscally feasible. The data may be al ready collected for other purposes, or may need to be collected specifically for the purposes of gauging progress towards SFM .

Understandable - indicators must be understandable not only to forest managers but also to the informed public, especially if public interests are to be incorporated into forest planning exercises. Simplicity and clarity are also characteristics that make indicators more understandable.

Can be Forecast - Future indicator behaviour should also be predictable with reasonable accuracy, if they are to guide management or policy decisions. It must be possible to make an assessment of future indicator behaviour, given certain management actions, policies or other factors.

Have Reference Values - Indicators often have their strongest meaning when forest managers or policy makers are able to compare their performance against reference values, and subsequently to design actions to induce indicator performance in some desired future direction. Where feasible, indicators in the CCFM framework should include reference values/conditions, and the TWGs should make recommendations on how reference values may be used with the indicators they recommend.

attention on important elements of sustainable forest management. Supporting indicators complement core indicators by providing more detailed information on the progress toward sustainable forest management in Canada. Potential indicators are future indicators that address important concepts, but which cannot currently be measured or properly defined. Potential indicators may identify areas where further research is warranted.

During the review process, the TWGs focused on developing quantitative indicators. In a few instances though, reasonable quantitative measures could not be developed, and qualitative or descriptive indicators provide a way of describing the current status of the value being measured, or trends in its maintenance.

$H$ aving Task Force members, or accepted alternates, chair the TWGs was very important to the success of this part of the review. The Chairs were able to use their policy expertise and knowledge of the CCFM C\&I initiative to more effectively guide the work of the TWGs. When the work of the TWGs was finished, the Chairs, as members of the Task Force, were able to effectively communicate, and defend, the work of the TWGs to their colleagues on the Task Force. As a result, the TWGs worked efficiently and did not stray outside the boundaries established by the Task Force, and the Task Force was able to give informed consideration to the TWG's recommendations.
Two important lessons weretaken away from thisstage of the review process. First, the technical review was very effort-intensive. Each technical expert gave about four to seven days over eight months, including time spent in ad hoc discussions with TWG members between meetings. The time allowed for a fulsome debate of the indicators within the TWGs while the spacing of the meetings allowed the experts to consult with others between meetings to determine such things as data availability, data needs and reporting costs. Second, the TWGs benefited immensely from sharing knowledge and experience throughout the review. This sharing of experiences and progress, through plenary sessions and a paper on cross-cutting issues that was developed and circulated, allowed the groups to learn from others, to hear suggestions for indicators, and to collectively develop solutions to common problems.

\section{Validate the revised C\&I with users}

The revised indicators recommended by the TWGs went a long way towards providing indicators that were more suitable and functional for the values, issues and concerns identified. Still, the indicators needed to be validated with government and non-government users to interpret them within the context of the different jurisdictions, legislations and policies of the provinces and territories, to ensure that the indicators reflected adequately the range of forest conditions across Canada, and to ensure that no significant values had been overlooked.

In M arch and April 2003, Task Force members reviewed the 53 indicators recommended by the TWGs, seeking input from agencies and departments within their governments. In M ay 2003, the Task Force hosted a discussion meeting on the revised indicators with potential users and stakeholders of the CCFM C\&I from the non-government community. The goal of the meeting was to help assess whether or not the revised indicators adequately addressed the values, issues and concerns of Canadians with regard to the sustainable use of their forests. Representatives from 35 nongovernment organizations from the Aboriginal, academic, industry and environmental communities were invited to attend or submit written comments. The Task Force made final revisions to the indicators in consideration of the comments received, resulting in a further paring of the list to 46 indicators.

\section{The Revised Framework}

In September 2003, the CCFM released its revised C\&I framework consisting of six criteria and 46 indicators. The criteria have not changed but have been reworded slightly to improve clarity. The number of indicators in the revised framework has been reduced, compared to the 1995 framework, by focusing on indicators that are most relevant to Canadians' values, are most often measurable with available data, and are understandable to policy makers, forest managers and an informed public. Links between the criteria have also been more explicitly defined and, in some cases, indicators address multiple values under different criteria. By using indicators more efficiently, the 2003 CCFM C\&l address the values, issues and concerns of Canadians while maintaining continuity with the 1995 framework; many of the values addressed by quantitative indicators in the 
original CCFM C\&I framework are addressed by similar indicators in the revised framework.

Thirty-six indicators in the revised framework have been identified as core indicators. These indicators raise public awareness and focus public attention on important elements of sustainable forest management. Ten supporting indicators complement core indicators by providing further information deemed important to reporting on SFM. The CCFM opted not to use the term potential indicators, as they felt that all of the indicators ultimately selected were sufficiently well-defined and had sufficient data to produce a report, even if the initial report is only a case study using regional data.

The 2003 C\&I framework is intended to provide a better understanding of what is meant by sustainable forest management in the Canadian context. The 1995 C\&I framework was considered a "living document," capable of evolving further as our knowledge advanced. This revision shows that the framework is adaptable, reflecting changes in Canadian values and concerns, while also ensuring that the indicators are as suitable and functional as possible. The $c \& \mid$ framework continues to identify those elements of the forest ecosystem, as well as our social and economic systems, that must be sustained or enhanced.

The criteria and indicators represent a comprehensive framework. It is recognized that no single criterion or indicator alone is an indication of sustainability; rather, the individual criteria and indicators must be considered in the context of other criteria and indicators. Throughout the review, the forest was recognized to be a system with many linkages, which cannot easily be broken down into compartments. As such, values and concerns under one criterion may be linked to indicators under another criterion. Capitalizing on such linkages made it possible to reduce the number of indicators.

The revised indicators are designed for reporting at the national level. While some indicators lend themselves to reporting at the ecozone level or the provincial/territorial level, the indicators are not intended to assess sustainability directly at a local or forest management unit level. Still, in the past, the CCFM C\&I framework has provided a starting point for developing sub-national $C \& \mid$ frameworks, and the revised framework should continue to do the same.

M embers of the forest industry, academia and the EN GO community, have supported the revised framework. However, some members of the Aboriginal community expressed a desire to add a seventh criterion to the framework dealing exclusively with Aboriginal issues in sustainable forest management. The CCFM gave careful consideration to this, but in the end felt that the six criteria in the framework are broad enough to cover all environmental, economic and social aspects of sustainable forest management.

\section{Next Steps}

The CCFM has agreed to produce its next C\&I report, using the revised framework, in 2005. This will require a coordinated effort on the part of the federal, provincial and territorial governments to determine reporting priorities, identify the data needs, establish data collection protocols, compile the data from various sources, and interpret the trends.
Work has begun on preparing and producing the 2005 C\&I report. While data should be available for most indicators in the revised framework, gathering sufficient data for some indicators dealing with values not traditionally dealt with in forest management will be a challenge. This includes, for example, non-timber forest products and Aboriginal and treaty rights.

The development of the technical supplements by the TWGs, which describe each indicator in detail, have greatly facilitated the quick identification of knowledge gaps and research needs in the $C \& \mid$ framework. The technical supplements have also been used to quickly develop a set of data templates and data submission forms, which are being used by jurisdictions to submit their required data for the 2005 report.

Internationally, Canada is a member of the Montréal Process and information from CCFM C\&I reports has formed the basis for Canada's contribution to Montréal Process reports in the past. During the CCFM C\&I review, the TWGs carefully examined the M ontreal Process indicators. The revised CCFM C\&I are compatible with morethan 50 of the M ontreal Process's 67 indicators, while at the same time providing more detail and precision on values of importance to Canada. This will facilitate Canada's future international reporting. In addition, the CCFM C\&I review will provide a basis for Canada's cooperation in and contribution to developing and revising the Montréal Process criteria and indicators.

\section{Future Challenges}

One of the challenges involved in evaluating progress toward sustainability is linking the indicators under the various criteria to make an overall assessment. During the review process, the TWGs were asked to try and identify reference values, such as baselines, targets or thresholds, which could provide context for assessing the indicators. Because sustainability measures are still evolving, and because most of the forest management decision-making responsibility resides at the provincial and territorial level in Canada, few identifiable national targets or thresholds have been established. Most of the reference values identified by the TWGs are baselines of past performance. However, this is not uncommon in national level C\&I initiatives (Hendricks 2003) and baselines still provide important context for indicators, allowing for the determination of the direction of a trend and the rate of change in a trend, which are important in guiding policy and management decisions.

Work on developing more sophisticated tools and techniques to provide an overall assessment of sustainability is progressing. One promising tool appears to be the Multicriteria Analysis (MCA) techniqueadapted for use with $C \& 1$ by CIFOR (Mendoza et al. 1999). So far, this technique seems to have been applied most extensively at the local level (M endoza and Prabhu 2000, 2003); however, the Province of Ontario has been exploring its use at the provincial level to provide an overall assessment of its progress toward sustainability based on its C\&I report (O M NR 2002). One possibleapproach to providing an overall assessment is to invite individuals from various sectors of society to score and weight each indicator in the report. The subsequent weighted scores can then be worked up into a score for each 
criterion or even an overall score. The scores from groups of individuals can then be statistically analysed to see how different sectors of society are evaluating progress toward SFM . This analysis can form feedback into the policy making forum, allowing for the devel opment of policies intended to raise indicator scores for some or all sectors of society.

Through the compilation of information for past CCFM $C \& \mid$ reports, it has become apparent that the key data and information holdings, covering a variety of data types and formats, are dispersed throughout federal, provincial, territorial and municipal agencies and institutions, and that $C \& \mid$ reporting could be greatly improved with the establishment of some key national initiatives. Foremost among these is a national mechanism to compile and provide timely and coordinated access to accurate forest information. Fostering collaboration between the various data gatherers, information custodians and user groups is critical to improving the nation's ability to report on the sustainability of its natural resources. Three CCFM initiatives will help address this issue. First, the National Forestry Database Program (NFDP), which currently collects and stores various data for forestry statistics in Canada, is to be expanded to collect and store the data required for all of the CCFM indicators. Second, the National Forest Information System (NFIS), when fully developed, will provide Canadians with access to data via the Internet. Third, a new national, forest inventory that will enabletrend estimates for many of the CCFM indicators is in development and will complement the NFDP and NFIS and enhance the nation's capacity to assess the sustainability of its forests.

\section{Conclusion}

Canada is a leader in the development and implementation of criteria and indicators of sustainable forest management. In 1992, Canada took its first steps to develop and report on a set of indicators to help track the nation's progress in achieving environmental, economic and social objectives (Forestry Canada 1992). In 1993, Canada hosted the Seminar of Experts on Sustainable Development of Boreal and Temperate Forests (CSCE 1994), where much of the early international development of $C \& I$ for sustainable forest management took place. N ow, criteria and indicators are recognized worldwide as one of the most effective tools for measuring progress toward sustainable forest management (FAO 2003, UNFF 2004), with some 150 countries involved in processes or initiatives on $C \& \mid$ for sustainable forestry (FAO 2001).

Canada has received many benefits from the development and implementation of its national $C \& \mid$ framework. The C\&I provide a framework for standardizing national forest data collection and for developing and implementing a national forest inventory. The sharing of information and resources between jurisdictions and stakeholders has helped to build capacity and reduce reporting costs, and the framework has been used to guide national research planning. The national framework has also led to the development of sub-national and local-level initiatives, which help to evaluate policies and regulations, facilitate meaningful public input, and guide forest practices. The revisions to the CCFM $C \& 1$ improve the ability of the framework to continue to provide these benefits and ensure that the $C \& I$ remain an important tool for helping Canada achieve sustainable forest management.

Much of the success of Canada's review of its national C\&l framework for sustainable forest management lies in the fact that it was based on an open, transparent process that engaged affected parties throughout the process and provided adequate follow-up to participants to ensure their support. In addition, the CCFM review process was able to adapt many of the tools and techniques developed for use in identifying sets of $C \& \mid$ at the sub-national level to use at the national level. Canada's experience with reviewing its indicators may serve as an example and model to other countries now considering reviewing their national $C \& \mid$ frameworks.

More information on the CCFM C\&I initiative can be found on the Internet at www.ccfm.org.

\section{Acknowledgements}

The authors gratefully acknowledge the hard work and dedication of all participants in the CCFM C\&I review. A list of participants can be found on the CCFM website. The authors also thank Ivy Chan for her thoughtful comments on this manuscript.

\section{References}

Canadian Council of Forest Ministers (CCFM). 1992. Sustainable Forests: A Canadian Commitment. Canadian Council of Forest M inisters. Ottawa. $51 \mathrm{p}$.

Canadian Council of Forest Ministers (CCFM). 1995. Defining Sustainable Forest M anagement: A Canadian Approach to Criteria and Indicators. Canadian Forest Service. Ottawa. $22 \mathrm{p}$.

Canadian Council of Forest Ministers (CCFM ). 1997. Criteria and Indicators of Sustainable Forest M anagement in Canada: Technical Report 1997. Canadian Forest Service. Ottawa.137 p.

Canadian Council of Forest Ministers (CCFM). 1998. National Forest Strategy 1998-2003 - Sustainable Forests: A Canadian Commitment. Canadian Council of Forest M inisters. Ottawa. $47 \mathrm{p}$. Canadian Council of Forest Ministers (CCFM). 2000. Criteria and Indicators of Sustainable Forest M anagement in Canada: National Status 2000. Canadian Forest Service. Ottawa. 122 p.

Canadian Council of Forest Ministers (CCFM). 2003. Defining Sustainable Forest M anagement in Canada: Criteria and Indicators 2003. Canadian Council of Forest M inisters. Ottawa. 20 p.

Canadian Forest Service (CFS). 1994. Seminar of experts on sustainable development of boreal and temperate forests, Technical Report, Annex 1. Conference on Security and Cooperation in Europe, September 27 to October 1, 1993. Montréal, Canada. Canadian Forest Service. Ottawa. $145 \mathrm{p}$.

Compas Inc. 2002. Canadian Council of Forest Ministers Criteria and Indicators Framework Review: Focus Group Research. Report to the Canadian Forest Service. Compas Inc. Multi-Audience Research. Ottawa. $53 \mathrm{p}$.

Conference on Security and Cooperation in Europe(CSCE). 1994. Seminar of experts on sustainable development of boreal and temperate forests, September 27 to October 1, 1993. M ontréal, Canada, Technical Report, Annex 1. Canadian Forest Service. Ottawa. 145 p. Convention of Biological Diversity (CBD). 1996. Indicators for assessing the effectiveness of measures taken under the convention. Report to the Subsidiary Body on Scientific, Technical and Technological Advice, $2^{\text {nd }}$ M eeting, Montreal, 2 to 6 September 1996. Report Number UNEP/CBD/SBST TA/2/4. CBD Secretariat. Montreal. $16 \mathrm{p}$.

Duinker, P. 2001. Criteria and indicators of sustainable forest management in Canada: Progress and problems in integrating science 
and politics at the local level In A. Franc, O. Laroussinie, T. Karjalainen (eds.). Criteria and Indicators for Sustainable Forest $M$ anagement at the Forest Management Unit Level, European Forestry Institute Proceedings No 38. Joensuu, Finland.

Food and Agriculture O rganization (FAO) of the United Nations. 2001. Criteria and Indicators for Sustainable Forest M anagement: A Compendium. Forest M anagement Working Papers, Working Paper 5, Forest Resources Development Service, Forest Resources Division, FAO, Rome. 68 p.

Food and Agriculture O rganization (FAO) of the United Nations. 2003. Report on the International Conference on the Contribution of Criteria and Indicators for Sustainable Forest M anagement: The Way Forward (ClCl 2003) 3-7 February, Guatemala City, Guatemala, VolumeI and II. FAO. Rome.

Forestry Canada. 1992. The State of Canada's Forests: 1991. Forestry Canada. Ottawa. 85 p.

Global Reporting Initiative. 2000. Sustainability Reporting Guidelines on Economic, Environmental and Social Performance. Global Reporting Initiative, Boston, M A.

Hendricks, R. 2003. Strengthening the elaboration and application of criteria and indicators for sustainable forest management In Food and Agriculture Organization (FAO) of the United Nations. 2003. Report on the International Conference on the Contribution of Criteria and Indicators for Sustainable Forest M anagement: The Way Forward (ClCl 2003) 3-7 February, Guatemala City, Guatemala, Volume II. pp. 37-57. FAO. Rome. 163 p.

International Institute for Sustainable D evelopment (IISD). 2000. What are the general selection criteria for indicators? http://iisdl. iisd.ca/measure/faqcriteria.htm (Accessed Jan 27, 2002.).

International Institute for Sustainable D evelopment (IISD). 2004. Earth Negotiations Bulletin 13:1-12.

Mendoza, G.A. and P. Macoun with R. Prabhu, D. Sukadri, H. Purnomo and H. Hartanto. 1999. Guidelines for Applying MultiCriteria Analysis to the Assessment of Criteria and Indicators. Center for International Forestry Research. Jakarta, Indonesia. $85 \mathrm{p}$. Mendoza, G.A. and R. Prabhu. 2000. Multiple criteria decision making approaches to assessing forest sustainability using criteria and indicators: a case study. Forest Ecology and M anagement 131: 107-126.

Mendoza, G.A. and R. Prabhu. 2003. Qualitative multi-criteria approaches to assessing indicators of sustainable forest resource management. Forest Ecology and M anagement 174: 329-343.

Ministerial Conference for the Protection of Forests in Europe. 2001. Background document on the evaluation of Pan-European indicators. First M CPFE workshop on the improvement of PanEuropean indicators for SFM, 26-27 March, 2001, Triesenberg, Liechtenstein.

Montréal Process. 2003. Report on the $15^{\text {th }}$ meeting of the working group on criteria and indicators for the conservation and sustainable management of temperate and boreal forests - M ontréal Process. Available online at http://www.mpci.org/meetings/ 15_e.html. (Accessed on August 26, 2004).
National Forest Strategy Coalition (NFSC). 2003. National Forest Strategy 2003-2008 - A Sustainable Forest: The Canadian Commitment. National Forest Strategy Coalition, Ottawa. 26 p.

Natural Resources Canada. 1997. Tracking Survey of Canadian Attitudes Towards Natural Resources Issues, 1997. Natural Resources Canada, Ottawa.

Natural Resources Canada. 2000. A user's guide to local level indicators of sustainable forest management: experiences from the Canadian Model Forest Network. Natural Resources Canada, Ottawa. $265 \mathrm{p}$.

Ontario Ministry of Natural Resources (OMNR). 2002. State of the Forest Report: 2001. Queen's Printer for O ntario. Toronto.

Prabhu, R., C.J.P. Colfer and R.G. Dudley. 1999. Guidelines for Developing, Testing and Selecting Criteria and Indicators for Sustainable Forest M anagement. Center for International Forestry Research. Jakarta, Indonesia. 186 p.

Robinson, D.W., A. Hawley and M. Robson. 1997. Social valuation of the M cGregor M odel Forest: Assessing Canadian public opinion on forest values and forest management. Report to the M cGregor Model Forest Association.

Sanderson, L., K. Beesley, and R. Colborne. 2000a. Public Perceptions and Attitudes toward sustainable forest management: central Nova Scotia, 2000: report for the Nova Forest Alliance. Rural Research Centre, Nova Scotia Agricultural College, Truro, NS. 80 p.

Sanderson, L., R. Colborne and K. Beesley. 2000b. Woodland O wners' Perceptions and Attitudes toward sustainable forest management: central Nova Scotia, 2000: report for the Nova Forest Alliance. Rural Research Centre. Nova Scotia Agricultural College, Truro, NS. 94 p.

Smith, C.T., A.T. Lowe and M .F. Proe. 1999. Indicators for sustainable forest management. Papers presented at the IEA Bioenergy Task XII Workshop held in Eddleston, Scotland, 20-25 September 1997. Forest Ecology and M anagement 122: 1-5.

United Nations Forum on Forests (UNFF). 2004. Criteria and Indicators of Sustainable Forest Management. Report of the Secretary General to the United Nations Forum on Forests, $4^{\text {th }}$ Session. Report Number E/CN .18/2004/11. U NFF Secretariat. New York. $21 \mathrm{p}$.

United States Department of Agriculture (USDA) Forest Service. 2002. Sourcebook on criteria and indicators of forest sustainability in the Northeastern area. NA-TP-03-02. USDA, Newtown Square, PA. 64 p.

Von Mirbach, M. and L. Johnson. 1998. Local level indicators for the Eastern Ontario Model Forest. EOMF Information Report No. 43. EOM F, Kemptville, ON.

Williams, J., P. D uinker and C. Wedeles. 1998. Assessing progress in sustainable forest management: proposed criteria and indicators for the U pper Great Lakes Region. Report to the Great Lakes Forest Alliance. Arborvitae Environmental Services Ltd. Toronto. ON . 